\title{
Resenha do livro The H-Word: The Peripeteia of Hegemony
}

\section{João Pedro de Toledo Piza e Moraes Sarmento ${ }^{1}$}

\begin{abstract}
Resumo
Esta resenha busca realizar uma síntese crítica do livro The $\mathrm{H}$-Word: The Peripeteia of Hegemony, de Perry Anderson, cujo objetivo principal é traçar uma história do conceito de hegemonia na teoria política. Comenta-se a transformação da sua concepção teórica, dos usos mais elementares, na Grécia antiga, aos usos mais atuais. Além disso, são analisadas as contribuições de Antonio Gramsci para o pensamento da hegemonia, cruciais para a sua consolidação no vocabulário político moderno, bem como as de alguns de seus continuadores, como Hall, Laclau e Guha. Ao longo dessa história, um ponto fundamental retornará e se desdobrará reiteradamente: a tensão entre coerção e persuasão. Continuidades e descontinuidades entre esses dois elementos do conceito aparecerão em autores de diferentes países e épocas. Isto é, as ideias em relação ao que significa "hegemonia" flutuarão em um espectro que vai da dominação violenta (arkhé, império) à negociação consentida, quase nunca propondo a primazia absoluta de um dos polos, seja para compreender o equilíbrio pentárquico na Europa do século XVIII ou os Estados Unidos do século XXI. A resenha se concentrará na hegemonia conforme foi pensada no Ocidente, tendo em vista que a história milenar desse conceito na China e no Japão exigiria uma longa explicação de conceitos complexos para se fazer entender, e as nuances que a envolvem tornam injusto que se dedique apenas alguns parágrafos a ela. Assim, sendo preferível pecar pela omissão respeitosa que pela simplificação indecente, o capítulo em que Anderson trata da hegemonia no Oriente não foi resenhado neste trabalho.
\end{abstract}

Palavras-chave: hegemonia - hegemon - coerção - persuasão - Perry Anderson.

\footnotetext{
1 João Pedro de Toledo Piza e Moraes Sarmento. Aluno de graduação de Relações Internacionais na Pontifícia Universidade Católica do Rio de Janeiro. moraessarmento@hotmail.com
} 


\section{Abstract}

This paper seeks to draw a critical synthesis of the book The H-Word: The Peripeteia of Hegemony, written by Perry Anderson, whose main objective is to write a history of the concept of hegemony in political theory. We comment the transformation of this theorical conception from its most ancient uses in Ancient Greece to its most recent ones. Besides that, we analyze contributions of Antonio Gramsci to thinking about hegemony, which were crucial to its consolidation in the modern political vocabulary, as well as the contributions of some of his followers, such as Hall, Laclau and Guha. Throughout this history, one fundamental aspect will return and unfold itself repeatedly: the tension between coercion and persuasion. Continuities and discontinuities between these two elements of the concept will appear in authors from different times and places. That is, ideas in relation to what "hegemony" means will generally float in a spectrum from violent domination (arkhé, empire) to consented negotiation, rarely proposing the absolute primacy of one of these poles, be that to comprehend the equilibrium of 18th century Europe or of 21 st century USA. The paper will focus on hegemony as it is understood in the West, given that the millennial history of that concept in China or Japan would demand a long explanation of complex concepts to make itself feasible, and the nuances that involve this history make it unfair to dedicate only a couple of brief paragraphs to it. Since it is better to $\sin$ by respectful omission than by indecent simplification, the chapter in which Anderson deals with hegemony in the East was not reviewed in this paper.

Keywords: hegemony - hegemon - coercion - persuasion - Perry Anderson.

Perry Anderson é um dos mais renomados intelectuais vivos. Historiador por formação, o britânico, nascido em 1938, escreve há mais de meio século sobre diversos temas das humanidades a partir de uma perspectiva marxista ocidental. Editor do New Left Review por décadas, teve algumas de suas obras como Passagens da Antiguidade ao Feudalismo e Linhagens do Estado Absolutista incorporadas ao que pode ser chamado de cânone marxista.

The H-Word: The Peripeteia of Hegemony, publicado em 2017 pela Verso, consiste num estudo histórico acerca do conceito de hegemonia, desde seu surgimento na Grécia antiga até os dias atuais. Com mais de dois milênios de 
existência, tal termo foi empregado em ambientes muito distintos por teóricos de múltiplas orientações políticas, com conotações divergentes emergindo a partir dessa diversidade. No entanto, Anderson acredita que há um padrão nesse conjunto de significados para um mesmo significante. Desde Tucídides, há certas tensões subjacentes aos sentidos do termo, que permanecem. O cerne dessas tensões é a relação entre um elemento de coerção e um elemento de consentimento na hegemonia, problemática presente em todas as teorizações do conceito apresentadas, como se verá.

No capítulo 1, o autor apresenta as origens do termo na Grécia antiga e seu renascimento, mais de dois mil anos depois, na Prússia. "Hegemonia" surge como um substantivo abstrato pela primeira vez em Heródoto, para denotar a liderança pontual de uma liga de cidades-estado juridicamente iguais. Tal era a posição de Esparta nas Guerras Persas, por exemplo. À época, o termo coexistia com outro que indicava, mais genericamente, domínio: arkhē. A relação entre os dois conceitos é complexa. Heródoto e Xenofonte os usavam intercaladamente, como se os entendessem como sinônimos. Tucídides tentou separá-los, criticando a passagem de Atenas de uma posição de hegemonia para uma de arkhē sobre os gregos como a principal causa da Guerra do Peloponeso. Mas mesmo Tucídides nem sempre foi coerente; alguns personagens de seus textos usam os dois termos de forma ambígua. A Péricles, elogiado e imortalizado por Tucídides, são atribuídas falas em que declara abertamente ser a arkhē, e não a hegemonia, o maior motivo de orgulho do povo ateniense. Percebe-se, portanto, uma espécie de continuidade conceitual entre os dois termos até sob a perspectiva daqueles que tentavam separá-los. Se não sinônimos, hegemonia e arkhē eram dificilmente demarcáveis em definitivo, como "quente" e "morno".

Com a derrota de Atenas na Guerra do Peloponeso, a arkhē, agora pertencente a Esparta, ganha conotações definitivamente negativas para o ateniense Isócrates. Rogando aos gregos para que se unam novamente contra os persas, Isócrates defende o merecimento da hegemonia ateniense sobre uma liga grega por seus méritos culturais, que deveriam persuadir outras cidades-estado a aceitar sua preponderância política. Essa hegemonia desejada é idealizada como metonímia do poder da palavra sobre todas as outras coisas - hapantōn hēgemona logon. Para Perry Anderson, não se encontra defesa mais veemente da hegemonia como preeminência consentida por meio da persuasão. Historicamente, tal consentimento não se materializou. Pelo contrário; Isócrates viveu para ver Filipe II da Macedônia, pai de Alexandre, usar da força para intitularse formalmente Hegemon da Grécia. Aristóteles, olhando em retrospecto as 
hegemonias espartana e ateniense, e vivendo na macedônica, descreve todas as hegemonias como intrinsecamente intervencionistas. Tal visão cínica certamente foi influenciada pelos termos da Liga de Corinto macedônica, na qual o Hegemon tinha o direito de intervir contra quaisquer mudanças constitucionais nos Estadosmembros, ainda que estes formalmente continuassem seus iguais.

Após Aristóteles, o termo submerge por dois milênios, não constando nos léxicos políticos romano, medieval e moderno (Hobbes sequer o emprega em sua tradução da Guerra do Peloponeso, de Tucídides), e reemergindo só na década de 1840, na Prússia. Intelectuais favoráveis à unificação alemã fazem analogias entre o mundo grego, supostamente revigorado pela hegemonia macedônica, e o mundo alemão, rogando aos prussianos para que exerçam os papéis de Filipe e Alexandre e assumam a hegemonia na Confederação Germânica. Tal visão foi propagandeada por historiadores clássicos renomados, como Droysen e Pfizer. Com a unificação alemã, em 1871, tal analogia praticamente desaparece, não sendo conveniente à coroa alemã falar em hegemonia prussiana, conceito potencialmente divisivo. O termo submerge novamente.

No segundo capítulo, são expostas as origens dos usos de tal palavra em movimentos progressistas e revolucionários. Na Rússia tzarista da virada do século XX, o termo passa a ser usado por militantes de esquerda para definir relações políticas não entre Estados, mas dentro de Estados. Pavel Axelrod e Georgi Plekhanov argumentam que caberia ao proletariado russo liderar um movimento revolucionário mais amplo contra a autocracia. $\mathrm{Na}$ perspectiva marxista desses pensadores, a burguesia russa era fraca demais para conduzir uma revolução burguesa no país, o que criava uma oportunidade única para os proletários. Esta seria uma hegemonia como definida por Heródoto: liderança pontual e consentida num conflito específico, ainda que num conflito infra estatal. Lenin defende que os marxistas abracem todas as causas de potenciais aliados, de camponeses e minorias religiosas a profissionais liberais. Numa eventual vitória revolucionária, reinaria a ditadura do proletariado sobre classes inimigas e uma hegemonia sobre classes aliadas. Tal distinção reforça a concepção de hegemonia como preponderância consentida por meio da persuasão. Com a derrubada do regime tzarista em 1917 e a concretização da previsão de Trotsky, de uma transição direta para o socialismo, em detrimento da previsão de Lenin, o russo para de usar o termo em seus escritos. A coerção havia prevalecido sobre a persuasão.

O conceito bolchevique de hegemonia foi institucionalizado nos documentos fundadores da Internacional Comunista. Foi por meio deles que 
Antonio Gramsci teve contato pela primeira vez com o termo. Preso por Mussolini na década de 1920, Gramsci coloca a hegemonia como um conceito central em seus escritos. Apesar de fragmentários e incompletos, os Cadernos do Cárcere apresentam inúmeras inovações conceituais. O autor generaliza o termo para além de suas aplicações revolucionárias, definindo-o como qualquer forma estável de dominação por uma classe social. Gramsci também o altera em relação a suas origens russas, ao reconhecer o papel da coerção em sua manutenção. A hegemonia seria polivalente, impossível sem persuasão e impraticável sem coerção. Da adesão de aliados a uma causa comum, o termo passa a significar a submissão de adversários a uma ordem inimiga à deles. Mas ainda que a violência seja crucial - existiria um substrato militar em toda luta política -, Gramsci dá grande atenção à dominação ideológica, isto é, à extração do consentimento alheio. Segundo o italiano, tal preeminência ideológica se tornaria possível com uma sociedade civil robusta, com intelectuais em quantidade razoável defendendo constantemente a ordem hegemônica. Observando as diversas derrotas das forças revolucionárias na Europa após a Primeira Guerra, Gramsci defende que os comunistas parem de buscar uma vitória militar e passem a disputar o campo cultural e ideológico no Ocidente. Para Perry Anderson, como se verá, tais reformulações do conceito de "hegemonia" serão as mais frutíferas.

O terceiro capítulo apresenta o renascimento do conceito no campo das relações políticas interestatais. No período entre as duas guerras mundiais, Heinrich Triepel, jurista alemão conservador, publica um amplo trabalho sobre a história da hegemonia nas relações internacionais. A partir de uma perspectiva realista clássica, de acordo com a qual a busca por poder é intrínseca à política, Triepel distingue a hegemonia, que seria uma liderança internacional reconhecida, da herrschaft, dominação bruta, análoga à arkhē. Para o alemão, a hegemonia existiria em condições bem específicas. Precisaria haver uma ameaça externa para que um grupo de Estados do mesmo tipo se unisse. Os exemplos, portanto, seriam limitados; quase nenhuma das grandes potências europeias poderia ser chamada de hegemônica, seguindo tais critérios. Assim como Tucídides, o autor também enxerga nas hegemonias uma forte tendência de degeneração para a herrschaftlarkhē. Tal degeneração se daria porque o termo existiria dentro de um espectro, localizando-se entre a dominação bruta e a mera influência política.

Após a derrota alemã na Segunda Guerra, dois historiadores alemães se apropriam dos conceitos de Triepel, apresentados no quarto capítulo. Para Ludwig Dehio, a história europeia desde a Renascença é uma sequência de tentativas, por parte de diferentes Estados, de destruir o equilíbrio de poder do continente e 
obter hegemonia. Tais candidatos a hegemon foram sucessivamente derrotados por coalizões dos chamados wing powers: países dos "cantos" da Europa que se aliavam para contrabalancear essas ameaças (como os russos, otomanos, holandeses e britânicos). Definições de hegemonia, entretanto, não são apresentadas, o termo sendo empregado mais como um objetivo a ser alcançado do que propriamente como um conceito definido. Caberia ao historiador Rudolf Stadelmann apresentar uma resposta às teses de Dehio, bem como uma definição de hegemonia para essa geração intelectual. Stadelmann acreditava que, desde o século XVIII, as relações internacionais europeias haviam sido reguladas por um equilíbrio de poder mantido pela "pentarquia": Rússia, Prússia, Áustria, França e Reino Unido. Tais poderes teriam se organizado sucessivas vezes para impedir a primazia de um deles sobre todos os outros. Para Stadelmann, entretanto, hegemonia não seria o nome dessa eventual primazia, mas uma face crucial do equilíbrio de poder conscientemente mantido pela pentarquia. $O$ alemão acreditava que apenas por meio da combinação de força e credibilidade respeitável, presentes nos poderes pentárquicos, a manutenção de tal ordem era possível. O nome desse equilíbrio entre poder coercitivo e poder persuasivo seria hegemonia. Assim, apesar de terem posições ideológicas próximas, os conceitos de hegemonia de Dehio e Stadelmann eram muito distintos.

Outro par de teóricos realistas da hegemonia é apresentado no quinto capítulo: Hans Morgenthau e Raymond Aron. Escrevendo no auge da Guerra Fria, Morgenthau acredita na existência de um animus dominandi nos seres humanos que torna a política internacional uma luta por poder. Morgenthau define como imperialista uma política internacional que visa a derrubada do status quo, sendo a hegemonia apenas o termo dado a manifestação continental desse revisionismo. Como Dehio, Morgenthau apenas apresenta tal conceito como objetivo de certos países, não definindo-o por extenso. Já Aron, como Stadelmann, ao teorizar mais sistematicamente as relações internacionais, formula uma definição própria. O francês considera a hegemonia um dos três tipos de paz, ao lado de equilíbrio e império. No equilíbrio, os membros de um sistema internacional possuem poder similar, desencorajando o conflito; paz hegemônica se daria quando um país possui mais poder que qualquer outro, mantendo uma ordem internacional à sua imagem. No império, a desigualdade de poder é grande a ponto de o país preponderante absorver outros Estados. Aron descreve a posição estadunidense na Europa após a Segunda Guerra como hegemônica, enquanto na bacia caribenha o país havia estabelecido uma paz imperial desde 1898. Seguindo a tradição iniciada com Tucídides, Aron vê fortes tendências de transformação da 
hegemonia em império, ambas formas pertencendo ao mesmo continuum conceitual.

Segundo Anderson, um conjunto de fatores tornou o debate sobre hegemonia central nos Estados Unidos a partir da década de 1970. O autor argumenta no sexto capítulo que a derrota na guerra do Vietnã, o fim do sistema de Bretton Woods, o choque do petróleo e a instabilidade política internacional geraram um sentimento de crise sem precedentes entre os cidadãos estadunidenses. Charles Kindleberger argumenta que os EUA estavam abrindo mão de fornecer bens públicos internacionais como um mecanismo de provimento de liquidez, um arranjo institucional gerador de previsibilidade e capital em abundância. A estabilidade do sistema internacional dependia, durante o século XIX, da provisão desses bens pelo Reino Unido. Kindleberger não usa o termo "hegemonia", que para ele conota violência, mas sua ideia acaba conhecida como teoria da estabilidade hegemônica. Robert Keohane e Joseph Nye criticam-na, defendendo a tese de que, apesar de ter havido uma hegemonia estadunidense imediatamente após a Segunda Guerra, ela não existiria mais e nem seria necessária, sendo os EUA apenas mais um participante, ainda que particularmente poderoso, de uma economia transnacional marcada pela interdependência.

Robert Gilpin, concordando com a tese de Kindleberger de que regimes internacionais dependeriam de "fiadores", constitui sua própria teoria sistemática da hegemonia. Ele concebe a história das relações internacionais como uma série de ciclos de ascensão e queda de hegemonias em função do crescimento diferenciado do poder e prestígio de certos países. Em períodos de estabilidade, a submissão de países a uma ordem internacional seria garantida pela diferença de poder entre eles e os fiadores da ordem. A instabilidade surgiria na medida em que tal diferença diminuísse e gerasse incentivos para desafiar a hegemonia. Existiria uma tendência de diminuição dessas diferenças, visto que a manutenção da ordem tem um custo material alto e que a difusão tecnológica reduz ainda mais os hiatos de poder. Guerras hegemônicas seriam momentos decisivos em que um ator tentaria militarmente suplantar o outro como hegemon, possivelmente recomeçando o ciclo. Na concepção de Gilpin, a hegemonia possuiria elementos políticos e militares, mas Anderson considera relevante que, nesse debate estadunidense, o termo ganhe fortes conotações econômicas, o que é inédito.

No sétimo, oitavo e décimo capítulos, o autor se debruça sobre o legado de Gramsci em teorizações posteriores do conceito. Lamentando a "esterilização" do legado gramsciano na Itália pelo péssimo uso da obra do autor feito pelo 
Partido Comunista do país, usando vulgarmente seu nome e prestígio para justificar a posteriori qualquer posição, Perry Anderson afirma que os melhores frutos do trabalho de Gramsci estão fora de sua terra natal. Assim, Anderson analisa cinco autores anglófonos que desenvolveram, a partir da década de 1980, teorias explicitamente baseadas nas ideias do italiano.

Stuart Hall, jamaicano que emigrou ao Reino Unido na década de 1950, baseou-se num aprofundamento do conceito gramsciano feito por outro pensador, Raymond Williams. Este considera o termo mais substantivo do que noções marxistas clássicas de ideologia, constituindo um sistema de práticas, valores e significados que permeiam a consciência de uma sociedade, sendo necessário renová-lo e reconstruí-lo constantemente. Partindo dessa definição, Hall analisou a sociedade britânica do final da década de 1970 e fez previsões que, para Anderson, foram certeiras. Observando o recrudescimento da repressão e do discurso público contra fenômenos emergentes como novas subculturas jovens e um sindicalismo mais militante, Hall acreditava que a coerção estava se tornando cada vez mais presente na manutenção da hegemonia na sociedade britânica. Ao mesmo tempo, o jamaicano também via nos Conservadores movimentos no sentido de forjar uma coalisão social a fim de construir um novo senso comum no país. Liderados por Thatcher, os Tories estavam intuitivamente cultivando também o lado persuasivo da hegemonia, moldando um discurso que tornava natural as políticas sociais neoliberais que eles visavam implantar. Apesar de achar Hall visionário, Anderson critica sua desatenção ao contexto internacional, faltando uma abordagem sobre a difusão do neoliberalismo no restante do mundo.

O argentino Ernesto Laclau, como Hall, também fez suas contribuições teóricas a partir do Reino Unido. Um peronista de esquerda, Laclau desenvolve junto à belga Chantal Mouffe uma abordagem pós-estruturalista e pós-marxista do conceito gramsciano de hegemonia. Os dois criticarão a essencialização classista onipresente na literatura marxista, bem como a metanarratividade e a violência presentes nesses discursos. Entretanto, reconhecendo a eficácia da construção de coalisões sociais a partir de discursos persuasivos, Laclau defenderá o uso de tal tecnologia cultural para aprofundar e radicalizar a democracia. O argentino se tornará um dos poucos politólogos a falar em "populismo" sem uma conotação negativa, tornando-se um ideólogo de tal fenômeno político. Para ele, caberia aos atores políticos construir uma cultura nacional-popular que legitimasse e consolidasse na consciência coletiva os valores interessantes a tal movimento. Perry Anderson não esconde sua consternação com tal emprego do conceito 
gramsciano, que o transforma em ferramenta para grupos de qualquer orientação ideológica, dos marxistas aos fascistas.

Para Anderson, é possível que a melhor obra inspirada por Gramsci seja a do indiano Ranajit Guha. Com enfoque pós-colonial, Guha é fundador da escola dos estudos subalternos, que estuda a história do sul asiático a partir da perspectiva daqueles oprimidos pelas estruturas de poder locais. $O$ indiano constrói um modelo analítico das formas de poder que busca resolver certas ambiguidades em Gramsci. Guha subdivide a dominação e a subordinação, presentes em praticamente todas as relações do subcontinente indiano, em dominação por coerção, dominação por persuasão, subordinação por colaboração e subordinação resistida. Define, então, hegemonia como uma condição de dominação em que a persuasão excede a coerção. É importante notar que, segundo Guha, não existe hegemonia com coerção nula, pois não existe dominação sem algum grau de coerção; o que varia é a composição orgânica dessa dominação. Tal ponto é importante para evitar o erro, percebido pelo indiano em vários gramscianos, de tratar dominação e hegemonia como termos mutuamente excludentes.

Giovanni Arrighi, o quarto dos "herdeiros" de Gramsci analisados, é saudado por Anderson por unir, pela primeira vez no mesmo arranjo teórico, a hegemonia nas relações internacionais e a hegemonia doméstica gramsciana. A chave, aqui, é a economia. Segundo o italiano, hegemonia é um modelo de organização, produção e consumo que induz à aceitação e imitação universal dos valores de uma classe social de determinado país. Esse modelo traria vantagens materiais a tal classe ao mesmo tempo que persuadiria outros atores a aceitá-lo como benéfico. Arrighi acredita em ciclos de hegemonias que emergem pela acumulação de capital e decaem devido ao decréscimo gradual do lucro. Esses processos se dariam em grandes escalas, sendo o nível de análise internacional mais relevante do que o nacional, na visão do autor. Não havendo uma esfera cultural comum a toda a comunidade internacional, hegemonias tenderiam a ser mais coercitivas do que persuasivas, apesar dos dois elementos serem relevantes para sua manutenção. Robert Cox, o quinto autor gramsciano apresentado por Anderson, possui uma visão muito próxima da de Arrighi. O canadense também entende a hegemonia internacional como extensão de uma hegemonia doméstica, com ideias e instituições sendo construídas para a defesa dos interesses de uma classe social específica. Cox inova, entretanto, ao tratar da transnacionalidade dessa classe, que possibilitaria a identificação de mais indivíduos com a hegemonia. O neoliberalismo seria a ideologia da classe transnacional emergente. 
No décimo primeiro capítulo, Anderson muda seu foco de autores críticos à hegemonia para aqueles que, no século XXI, escrevem favoravelmente sobre tal objeto. John Ikenberry inicialmente recusava-se a usar o termo para definir a primazia dos EUA no mundo, mas posteriormente o aceitou. Para o estadunidense, seu país havia criado uma ordem hegemônica constitucional através de seu papel, fundando e solidificando arranjos normativos e possibilitando sua implementação mundo afora. Para Anderson, Ikenberry parte de sua simpatia à atual hegemonia para defender o fenômeno genericamente, afirmando que a diferença de tal constructo para um império é a existência de uma barganha, por vezes explícita, na qual o hegemon oferece bens e serviços àqueles que aceitam sua primazia. Paul Schroeder apresenta visão similar, distinguindo a hegemonia estadunidense de um império com base na inexistência de um centro único de poder e na possibilidade de coexistência com o direito internacional e o sistema moderno de Estados. Niall Ferguson, historiador britânico conservador, recusa a distinção feita por tais autores. Seria um erro acreditar que impérios pressupõem domínio direto, levando à crença de que é necessário um termo para dominações indiretas. Hegemonia seria um conceito descartável para Ferguson, que é simpático à existência de impérios por estes gerarem estabilidade ao mundo. Tanto Ikenberry quanto Schroeder reconhecem, entretanto, aquilo descrito desde Tucídides: continuidade conceitual entre hegemonia e império, diferenciáveis apenas por graus, com tendências de resvalo do primeiro para o segundo.

Perry Anderson trata de uma literatura muito específica no décimo segundo capítulo: aquela surgida na Alemanha para defender a hegemonia do país sobre a Europa contemporânea. Christoph Schönberger e Herfried Münkler argumentam que o tamanho da população e da economia do país, bem como sua posição geográfica, tornam natural sua posição hegemônica. Para além desses fatores, ambos afirmam que a política alemã, federativa e cheia de pesos e contrapesos, torna o país um laboratório perfeito para a liderança da União Europeia. Ambos retratam tal hegemonia como fardo, uma responsabilidade que a Alemanha nunca pediu e que deve aguentar. Münkler ainda argumenta que, paradoxalmente, a culpa pelos crimes nazistas torna o país o hegemon perfeito, pois tentações imperiais seriam contidas domesticamente. O passado conturbado traria maturidade política ao país, sendo a Alemanha bastião da estabilidade, da democracia, da austeridade e da moderação no continente europeu. Anderson enxerga nesse discurso contemporâneo a autopiedade engrandecedora típica dos 
impérios, outro exemplo de que a liderança numa federação, a primazia sobre outros países e o imperialismo fazem parte do mesmo arco conceitual.

No último capítulo, abordam-se brevemente dois autores realistas contemporâneos críticos à hegemonia. John Mearsheimer define hegemon como um Estado tão poderoso que domina todos os outros do sistema, afirmando também que tal posição sempre será, no máximo, continental, visto que os oceanos do planeta impedem a projeção de poder ilimitada. Após a Guerra Fria, a inédita unipolaridade do mundo fez os EUA estenderem seu poder para além dos mares, tentando espalhar democracias liberais, mas endividando-se e criando novos inimigos no processo. Mearsheimer chama tal fenômeno de "imperialismo liberal". Barry Posen concorda com tal diagnóstico, mas chama o fenômeno de "hegemonia liberal". Ele considera que esta é fruto de uma elite política ingênua, arrogante e desconectada da realidade. Para ambos autores, portanto, hegemonia é praticamente um sinônimo de império, de coerção, e não de persuasão.

Encerrando o capítulo e o livro, Perry Anderson reflete sobre o padrão de ambiguidades observado ao longo da história dessa palavra. Hegemonia seria um conceito supérfluo se significasse apenas legitimidade cultural ou poder coercitivo. Sua longa vida deve-se à capacidade de conjugar ambos, criando um espectro de possibilidades de uso. Do eufemismo simpático aos poderosos à crítica nuançada, "hegemonia" é um termo útil. Reconhecendo como recente a conexão entre seu uso nacional e internacional, Anderson aponta ainda o campo de estudos desse conceito que ele crê mais promissor: aquele focado na transnacionalidade. Se, domesticamente, coerção e persuasão tendem ao equilíbrio enquanto, internacionalmente, o primeiro prevalece devido à ausência de padrões culturais e normativos efetivos, o campo transnacional conjuga ambos de formas ainda pouco exploradas. Nesse sentido, trabalhos como os de William Robinson (2018) configuram o estado da arte do pensamento sobre a noção de hegemonia, explorando as formas como a classe capitalista transnacional se manifesta e se comporta. 


\section{Referências Bibliográficas}

ANDERSON, Perry. The H-Word: The Peripeteia of Hegemony. Nova York: Verso, 2017.

ROBINSON, William I.; SPRAGUE, Jeb. The Transnational Capitalist Class. In: JUERGENSMEYER, Mark; STEGER, Manfred; SASSEN, Saskia; FAESSE, Victor (Orgs.). The Oxford Handbook of Global Studies. Oxford: Oxford University Press, 2018. 